Коллекция гуманитарных исследований. Электронный научный журнал. The Collection of Humanitarian Researches. Electronic scientific journal

peer-reviewed $\bullet$ open access journal

ISSN 2500-3585

DOI: $10.21626 / j-c h r / 2021-4(29) / 1$

Психологические науки

УДК: 159.9:111.1:37

8

\title{
Онтологические регуяяторы личности в системе образования
}

\author{
(C) Е.Я. Малиновский
}

Мадиновский Е.Я. - доцент кафедры общей и медицинской психологии УО «Белорусский государственный университет» Минобра РБ

E-mail: eugeni.malinowski@gmail.com

Адрес: 220030, г. Минск, пр. Независимости, 4, Республика Беларусь

№4 (29) 2021 www.j-chr.com

\section{АННОТАЦИЯ}

Понимание неопределенности цели, при знаковом опосредовании развития высших психических функций субъекта, предполагает патерналистскую инициативу личностной ответственности, при которой академический либерализм Болонского процесса, приобретает онтологическую направленность знания: «Познаете истину и истина сделает вас свободными» [Ин 8:32].

Ключевые слова: онтология, образование, патернализм, наджинг. 
Термины «онтология» и «психология» ввёл в энциклопедический обиход Рудольф Гоклениус (R. Goclenius, 1590). Однако, задолго до него теология томистской метафизики, преемственно Аристотелю, рассматривает реальность неотделимой от Духа субстанцией (греч.

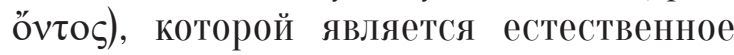
бытие (Фома Аквинский, 2005). Сущее есть, на самом деле, $\lambda$ ó $о \varsigma$ человека Слова, то есть личность. Онтологические взгляды формировались в дальнейшем Христианом Вольфом, неокантианцем Николаем Гартманом, Мартином Хайдеггером, Карлом Поппером (K.R. Popper, 1997). Науку бытия, объединяющую теологию, гуманистическую психологию и экзистенциализм Абрахам Маслоу назвал «0нтопсихологией, трансцендентальной психологией совершенства цели» (А. Маслоу, 2011). К концу прошлого века Антонио Менегетти означает области семантического поля базовой формы коммуникации, которая осуществляется на бессознательном уровне, и создаёт монитор отклонения человеческой психики, искажающего процесс восприятия реальности. При этом онто формальный разумный принцип, лежащий в основе исторического самосозидания в конкретности и силе образов, постигается посредством ключевых понятий и терминов: «женский ум в проекте жизни; мужской стиль; психосоматика; система и личность» [4]. Но без изначального сотворения [1, Быт 1:1], остаётся рутина, ведущая к burnout как профессиональному выгоранию. С другой стороны, феминное make love, not war, или «заниматься любовью, не войной» также требует онтологически выверенного анализа патернализма, о котором поведал миру Гераклит:

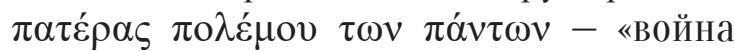
отец всего».

Онтологическое видение психологии образования предполагает созда- ние образовательных условий для ЭДИПа как аббревиатуры event drive informing paternity, или событийного вождения информированием, репатриирующем в субъекте идентификацию личности mit dem Vater der persönlichen Vorzeit - c Отцом личного правремения [5] через Логос как знак: «и вот вам знак: вы найдете Младенца в пеленах, лежащего в яслях» [1, Лк 2:12]. Репатриация эдипа это логическая креация образования, при котором абсолютное означающее Имени Отца» перестаёт оставаться несводимым к науке элементом сакральной этики, при котором университетский дискурс - «Воображаемое субъекта, при Символическом отношении нехватки бытия» [3]. Матрица учебных программ и планов так мотивирует психологию образования на рутину скрупулёзной дифференциации личности от индивида, субъекта и индивидуальности, как Венера заставляет «влюблённую» Психею отделять пшеницу от кучи перемешанных зерен в «Метаморфозах» Апулея. Без отцовской

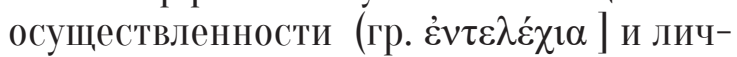
ной свободы подобный труд обречен на несчастье. Репатриация в образование образа Отца - процесс обратный экспатриации как инфантильной элиминации Его Имени из Им же сотворённого человека. С истории близнецов «сына полей» и «сына шатров», при том, что «больший поработает меньшему» [1, Быт 25:23], началось доминирование «Воображаемого» (Ж. Лакан) книжника (греч. $\beta 1 \beta \lambda i \alpha-\ll к н и-$ ги») над «Реальным» требованием «Чечевичной похлебки» [1, Быт.25:31] с братоубийственным умыслом [1, Быт 27: 41].

Актуальность программного исследования исходит из понимания ситуации образовательной неопределенности, при которой знаково-символические средства опосредуют развитие высших психических функций субьекта, неизбежно попадающего в «ситуацию бури-
№4 (29) 2021 www.j-chr.com

ТЕМАТИЧЕСКИЙ ВЫПУСК, ПОСВЯЩЕННЫЙ ЗО-ЛЕТИЮ СОЦИАЛЬНОЙ РАБОТЫ В РОССИИ

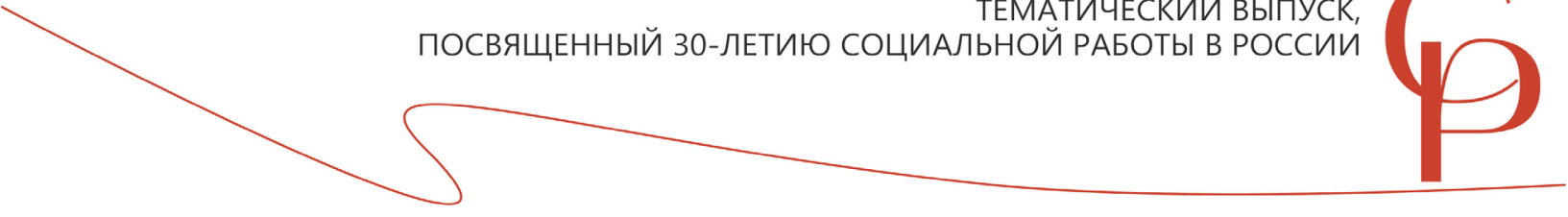


данова осла» между требованиями alma mater и principle of academic freedom and tenure - принципа академической свободы и ответственности. Академический либерализм, столь важный для Болонского процесса, необходим всем университетам. Однако образовательная система США предпринимает и патерналистское владение экономической ситуацией «Все труды человека - для рта его, а душа его не насыщается» [1, Еккл 6:7]. Так, в ходе теоретических и экспериментальных исследований, Нобелевский лауреат 2017 года по экономической психологии Ричард Тейлер разработал наджинг как «теорию подталкивания» (от идиш. - nudge - слегка подталкивающий локтем), учитывающей внимание к каждому внутреннему импульсу, а не только внешнему эффекту матерналистских детерминант. Выявление патерналистской предпосылки принятия решений, сопряжено с обеспечением чувства дружбы как владения, в том числе, совладание в coping strategy, или принятия непопулярных, но отдалённо справедливых решений [6].

Показалось существенным исследование такого критерия методологических затрат, при котором ограниченность рациональных ресурсов самоконтроля компенсируется стохастическим (греч. $\Sigma \tau o ́ \chi 0 \varsigma$ - предполагаемая цель) удовлетворением потребностей при nudge, «слегка подталкивающем» сопровождении выбора. Мы предположили, что психолого-образовательное решение цели благополучия сопряжено с несомненной любовью к личности Отца с встречным сопровождением мыслимого (cogito) сомнения (dubito) в Я (sum) субъекта, по Рене Декарту. Если, например, соискатель почётной должности учите-

№4 (29) 2021 www.j-chr.com ля, без сомнения, воспринимает её как свое собственное имя, то эта должность, точнее имя существительное, которое, по-дилетантски, решительно захватил соискатель, становится фракталом самоподобия, а сам «преподобный» из категории респондента сползает на уровень пациента с диагнозом «детская анимализация». Данная «схема-апперцепция» (А.Адлер) срабатывает в комплексе индивид-профессия при любой «занимаемой» (от греч. катохй) должности. Катексис (англ. cathexis; у З.Фрейда, Besetzung) как «символическая нехватка Бытия» [4] напоминает тот способ, посредством которого субстанциональная предпосылка «обналичивается» психической привязанностью вклада учителя в ученика, идею или вещь. При этом триада libido - lieben - любить в сопротивлении катексиса не мобильна перейти к новым объектам. Анимализация (от лат. anima animal - животное) может рассматриваться как запредельный катексис с фиксацией субъекта на зоне zoo politikos (Аристотель) как, при психотравматическом расстройстве «животного тела». По мнению Ж.Пиаже, инфантильная анимализация проявляется в неотличимости реальной жизни, воображаемого времени и символической позиции «минимум религии и максимум магии» (Эдвард Тейлор), при которой любые социальные отношения разрушаются примитивным мистицизмом. Фиксированный катексис с нарушением истинного значения слов «Бессознательным, структурированием язык, при котором я симптом» [3] служит нозологической инверсии (от лат. inversio «перестановка»). Так, если название романа Ф.М.Достоевского иллюстрирует языковую флексию слова «Подросток» в его реально-символическом комплексе, то нозология делается очевидной в названии «Идиот» как ídos «собственный», но не «безумный» (лат. moron) в русской версии этого слова. Символическая флексия является, по Ж.Лакану, отношением Бытия к нехватке онтологической реальности, при невежественной симво-

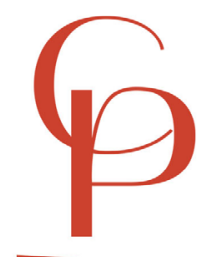

ТЕМАТИЧЕСКИЙ ВЫПУСК, ПОСВЯЩЕННЫЙ ЗО-ЛЕТИЮ СОЦИАЛЬНОЙ РАБОТЫ В РОССИИ 
лизации любви как реакции субъекта на alma mater парциального объекта. В глобальном масштабе жертвенной любви, лишение мира Имени Отца сопряжено с психотравматическим эдипальным комплексом, обрекающего индивида на EDIP со знаком минус как event deprivation informing patters - или лишение информации о событиях. Исследованию онтологического мышления и иммунного состояния EDIPa со знаком плюс как event drive informing personality или «событийное вождение информацией отца» отвечает стохастический метод (от греч.

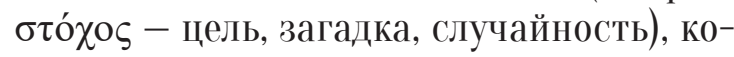
торый предполагает интенциональное внимание к возникающему (emergent) состоянию счастья как предсказанному, так и случайному [ср. 2, Еккл 9:11].

Любое детерминированное или вероятностное развитие процесса во времени, при стохастическом анализе, - по М. Кацу и Э. Нельсону, - может оказаться случайным (М. Kac \& J. Logan, 1976; E. Nelson, 1985). Существенным оказывается исследование такого критерия образовательного владения, при котором ограниченность рациональных ресурсов самоконтроля компенсируется стохастическим, предполагающим цель, удовлетворением потребностей при «слегка подталкивающем» (nudge) выборе. Результаты исследования И.В. Егорова показали статистически значимые различия по шкале «будущие события в России», при которой студенты религиозных вузов упоминают больше событий в будущем страны, чем студенты этого же возраста из светских вузов. С другой стороны, мировосприятие личности через такие сложные психологические феномены как зрелость и направленность, совершенствование себя и других, сочетание событий прошлого с настоящим понимания людей, деловых и межличностных взаимодействий, объемней и содержательнее представлено у студентов светских ВУЗов [3]. Предполагается, тем не менее, что религиозные респонденты, воспринимая настоящее между прошлым и будущим событием, ощущают Рождество и Воскресенье не как ожидаемое «знамение для рода сего» $[1$, Мф 12: 38], но входят в несомневающееся меньшинство непрестанного усилия [ср. 1, Мф 11:12].

Факторы присутствия (гр. $\pi \alpha \rho o v \sigma i ́ \alpha)$ Слова, именно, в высшем образовании личности сопровождаются показателем событийности event-drive informing personality (EDIP) в метаморфозе человека-эдипа, связанного проблемой идентификации любви как «иконы пола». В общем смысле, эдипальность это видимый способ организации субъекта существования, но не бытия личности. Причем, если в конце XIX века источником эдипальности была истерия, то источником как истерии, так и депрессии XXI века служит андрогинность с доминированием феминной составляющей над мускульной. Данные опроса студентов Минских университетов свидетельствуют, что депрессия интригует и дискредитирует радость образовательных достижений человека, при латентных половых ожиданиях. Причина нехватки таких ожиданий в событийной депривации event deprivation informing patters или EDIP со знаком минус. Фрейд, известно, не делал гомосексуализм и религиозность предметом психологических изысканий, смещая его к неврозу навязчивых состояний и наслаждению специфического нарративного типа. При этом, обсессиность служила в психоанализе нормальной образовательной характеристикой формирования Я-субъекта, при котором бессознательное напроч лишено каких либо половых дифференциаций и паттернов. По мнению Ж. Лакана у психотика нарушены отношения
№4 (29) 2021 www.j-chr.com

ТЕМАТИЧЕСКИЙ ВЫПУСК, ПОСВЯЩЕННЫЙ 30-ЛЕТИЮ СОЦИАЛЬНОЙ РАБОТЫ В РОССИИ

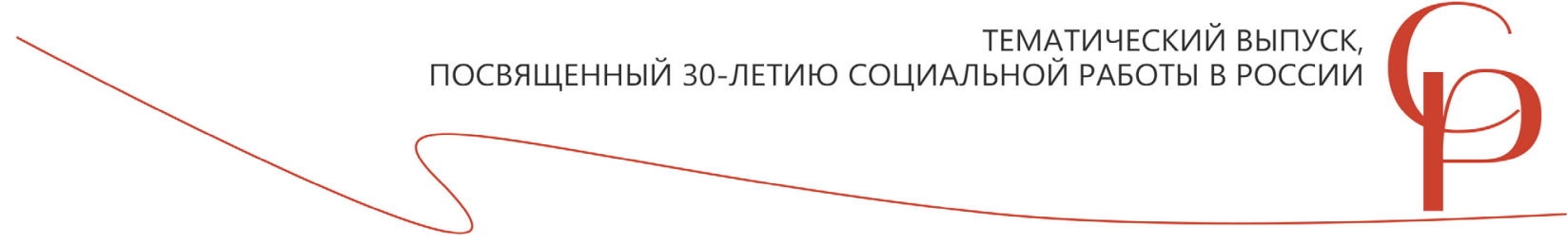


не с реальностью, к которой он весьма адаптирован, но с речью, лишенной коммуникации. Причем, если исходить из понимания education как the education of the will - воспитание воли, то станет очевидным исторический ракурс проблемы элиминации Имени вначале из официальной религиозно-догматической практики. Практика же символизации, а значит и инфантилизации сопровождала все остальные сферы культуры и гуманитарных наук, от тревожного ожидания Мадонны Рафаэля до «загадочного взгляда» Моны Лизы де Джоконда Леонардо да Винчи. Можно предположить, что EDIP это такая психологическая кольпоскопия недр, точнее влагалища (в греч. оригинале, ко́ $\pi о \varsigma)$ 0тца [Ин 1:18]. Психотравматический кольпит проявляется в гипотетической диагностике всех религий, за исключением религии Любви, исходя-

12

№4 (29) 2021

www.j-chr.com

\section{ЛИТЕРАТУРА}

1.Библия. Книги Священного Писания Ветхого и Нового Завета. - Текст : непосредственный. - М.: Изд-во Российское Библейское Общество, 2017. $1338 \mathrm{c}$.

2.Егоров, И.В. Профессиональная идентичность, групповая сплочённость студенческой молодёжи России и Белоруссии в контексте аттитюдов патриотизма: кросс-культурное исследование / И.В. Егоров. - Текст : непосредственный // Вестник Московского государственного областного университета. Серия: Психологические науки. - 2019. - № 3. - С. 90 - 104.

3.Лакан, Ж. Имена-0тца / Ж. Лакан. 368 с. щей от Отца и его Имени.

В итоге исследования, становится очевидным онтологическое согласование полноты информации о субъекте образованности с ее достоверностью. Информацию можно назвать полной, если ее достаточно для понимания и принятия решений. При этом, точность информации определяется степенью ее близости к реальному диалогу любви, а актуальность - важностью для настоящего, испытывающего кризис реализации бытия. Патерналистский наджинг EDIP определяется как способ выборки события и его обработки в плане реальности, апеллирующей к эпистемологии, выходящей за рамки ощущений, навыков и опыта. При этом, становление личности оказывается не только наблюдаемым процессом «укрощения строптивой» души, но и невидимой предпосылкой её образа.

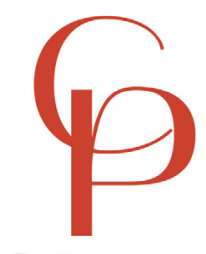

ТЕМАТИЧЕСКИЙ ВЫПУСК ПОСВЯЩЕННЫЙ ЗО-ЛЕТИЮ СОЦИАЛЬНОЙ РАБОТЫ В РОССИИ 


\title{
ONTOLOGICAL REGULATORS OF PERSONALITY IN THE EDUCATION SYSTEM
}

\section{(C) Eugeniy L. Malinovsky}

Eugeniy L. Malinovsky - Assosiate Professor of the General and Medical Psychology, Belarus State University E-mail: eugeni.malinowski@gmail.com

Address: 220030, Minsk, Prospect Nezavisimosty, 4, Respublic of Belarus

\begin{abstract}
Understanding the ambiguity of the goal and the symbolic mediation of the development of the higher mental functions of the subject, presupposes a paternalistic initiative of personal responsibility, in which the academic liberalism of the Bologna process acquires the ontological orientation of knowledge: "You will know the truth and the truth will make you free" [John 8:32].
\end{abstract}

Keywords: ontology, paternalism, education, nudge.

1.Bibliya. Knigi Svyashchennogo Pisaniya Vethogo i Novogo Zaveta. - Tekst : neposredstvennyj. - M.: Izd-vo Rossijskoe Biblejskoe Obshchestvo, 2017. - 1338 s.

2.Egorov, I.V. Professional'naya identichnost', gruppovaya splochyonnost' studencheskoj molodyozhi Rossii i Belorussii v kontekste attityudov patriotizma: krosskul'turnoe issledovanie / I.V. Egorov. - Tekst : neposredstvennyj // Vestnik Moskovskogo gosudarstvennogo oblastnogo universiteta. Seriya: Psihologicheskie nauki. - 2019. - №3. - S. 90 - 104.

3.Lakan, ZH. Imena-0tca / ZH. Lakan. -
Tekst : neposredstvennyj; per. A. CHernoglazova. - M.: «Gnozis», 2006. - $160 \mathrm{~s}$.

4.Menegetti, A. Ontopsihologiya. Praktika i metafizika psihoterapii / Antonio Menegetti. - Tekst : neposredstvennyj. - M.: NNBF «0ntopsihologiya», 2009. - 192 s.

5.Frejd, Z. YA i Ono / Z. Frejd. - Tekst : neposredstvennyj. - M.: Azbuka, 2021. - 288 s.

6.Taler, R. Novaya povedencheskaya ekonomika. Pochemu lyudi narushayut pravila tradicionnoj ekonomiki i kak na etom zarabotat' / R. Taler. - Tekst : neposredstvennyj . - M. : Eksmo, 2017. - 368 s.
№4 (29) 2021

www.j-chr.com

ТЕМАТИЧЕСКИЙ ВЫПУСК, ПОСВЯЩЕННЫЙ ЗО-ЛЕТИЮ СОЦИАЛЬНОЙ РАБОТЫ В РОССИИ

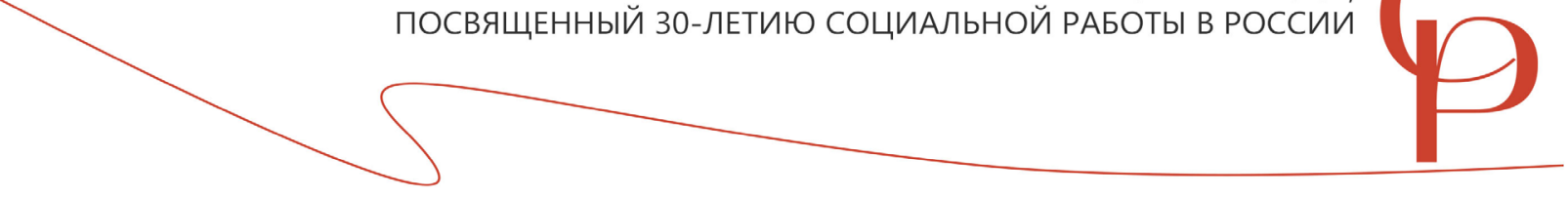

